\title{
CARBON DIOXIDE ACTIVATION BY Y ATOM AND Y' CATION IN THE GAS PHASE: A DENSITY FUNCTIONAL THEORETICAL STUDY
}

\author{
DE-MAN HAN, GUO-LIANG DAI*, ZHEN-ZHONG YAN, \\ CHUAN-FENG WANG, AI-GUO ZHONG
}

\author{
School of Pharmaceutical and Chemical Engineering, Taizhou University, Linhai, 317000, China.
}

(Received: July 14, 2009 - Accepted: December 17, 2009)

\begin{abstract}
The potential energy surfaces for the $\mathrm{Y}+\mathrm{CO}_{2}$ and $\mathrm{Y}^{+}+\mathrm{CO}_{2}$ reactions have been investigated by using the DFT (B3LYP/ECP/6-311+G*) level of theory. Both ground and excited state potential energy surfaces are discussed. The present results show that the reaction mechanism is an insertion mechanism along the $\mathrm{C}-\mathrm{O}$ bond activation branch. The reaction of $\mathrm{Y}$ atom with $\mathrm{CO}_{2}$ was shown to occur preferentially on the doublet PES throughout the reaction process. As for the reaction between $\mathrm{Y}^{+}$cation with $\mathrm{CO}_{2}$, it involves potential energy curve-crossing which dramatically affects reaction mechanism. Due to the intersystem crossing existing in the reaction process of $\mathrm{Y}^{+}$with $\mathrm{CO}_{2}$, the intermediate $\left(\mathrm{OY}\left(\eta^{2} \mathrm{CO}\right)\right)^{+}$may not form. This mechanism is different from that of $\mathrm{Y}+\mathrm{CO}$, system. All our theoretical results not only support the existing conclusions inferred from early experiment, but also complement the pathway and mechanism for this reaction.
\end{abstract}

Keywords: DFT theory, Potential energy surface, Intersystem, Yttrium

\section{INTRODUCTION}

As a long-lived greenhouse gas, carbon dioxide is a main contributor to global warming. How to remove it from industrial emission and to recycle this gas has been one of the most challenging subjects nowadays ${ }^{1}$. As it is very difficult to reduce significantly $\mathrm{CO}_{2}$ emissions from anthropic sources, in the past many years, considerable attention has been paid to convert this species into more useful chemical materials due to it's abundance and renewability. But new ways must be found to activate the molecule catalytically if its potential has to be realized. Activation is one of the effective routes to induce inert molecules to react. In previous years, many type of metal and metal oxide were used as catalysts to activate $\mathrm{CO}_{2}$, and much interest has been focused on the experimental and theoretical studies of transition metal- $\mathrm{CO}_{2}$ complexes ${ }^{2-40}$, as such complexes have potential for practical application in activating $\mathrm{CO}_{2}$.

In previous studies involving the reactions between metal and carbon dioxide, much attention have been paid to the transition metal and main group element atoms ${ }^{14-34}$. Sievers et al. ${ }^{13}$ have examined the reaction of $\mathrm{Y}^{+}$with $\mathrm{CO}_{2}$, where metal-oxygen bond energies were determined. In this reaction, $\mathrm{YO}^{+}$is found to be dominant product at the low energy condition. Zhou et al. ${ }^{7}$ reported an IR study on the reaction of laser-ablated $\mathrm{Y}$ atom with $\mathrm{CO}_{2}$, they also carried out a DFT calculation on the observed products OYCO and OY $\left(\eta^{2} \mathrm{CO}\right)$. But detailed information for the potential energy surfaces of reactions $\mathrm{Y}+\mathrm{CO}_{2}$ and $\mathrm{Y}^{+}+\mathrm{CO}_{2}$ are still scarce. Can a similar reaction mechanism be applicable to the reactions of $\mathrm{Y}$ atom and $\mathrm{Y}^{+}$cation with $\mathrm{CO}_{2}$ ? What are the different behaviors between them? Promoted by these questions, we investigated the reactions of $Y$ atom and $\mathrm{Y}^{+}$cation with $\mathrm{CO}_{2}$ by using DFT methods in order to shed some light on these reactions. A comparative theoretical study on the reactions of $\mathrm{Y}$ atom and $\mathrm{Y}^{+}$cation with $\mathrm{CO}_{2}$ is interesting and important since $\mathrm{Y}$ is a representative element of the second-row early transition metal.

\section{COMPUTATIONAL METHODS}

Both the ground and excited state PESs for the reactions of $\mathrm{Y}$ and $\mathrm{Y}^{+}$ with $\mathrm{CO}_{2}$ have been considered in detail. All molecular geometries (reactants, intermediates, transition states and products) were fully optimized at B3LYP level ${ }^{41,42}$. (It should be mentioned here the singlet species was optimized at RB3LYP level. As for the doublet, triplet and quartet species, we used UB3LYP method). This method is chosen in this study since the previous calibration calculations on transition metal compounds have shown that this hybrid functional provides accurate results for the geometries and vibrational frequencies of systems containing transitional metal cations ${ }^{43,44}$. In all of our calculations, the $6-311+\mathrm{G}^{*}$ basis set was used for the carbon and oxygen atoms, and the relativistic effective core potentials (ECP) of Stuttgar ${ }^{45}$ basis set were used for the Yttrium, the $5 \mathrm{~s}$ and $4 \mathrm{~d}$ in Y were treated explicitly by a (8s7p6d) Gaussian basis set contracted to [6s5p3d]. For nonmetal atoms, a standardized $6-311+\mathrm{G}^{*}$ basis set was used. The harmonic vibration analyses were performed at the same level of theory for all optimized stationary points to determine their characters (minimum or first-order saddle point) and to evaluate the zero-point vibrational energies (ZPEs). To verify whether the located transition states connect the expected minima, intrinsic reaction coordinate (IRC) calculations were carried out for each transition state at the same level ${ }^{46}$. All calculations in the present study were performed using the Gaussian 03 program ${ }^{47}$.

\section{RESULTS AND DISCUSSION}

In order to evaluate the computational accuracy, before the discussion on the mechanisms of the title reactions, we first presented the bond dissociation energies (BDE) for several species involved in the reaction of $\mathrm{Y}^{+}+\mathrm{CO}_{2}$ system. As shown in Table I, where some available experimental values are also listed for comparison, most of the theoretical values are in agreement with experimental findings. In the present work, our main goals are to examine the detailed mechanism of the reaction and obtain the relative energy level of the species involved, so the theoretical level chosen in this work is reliable for describing the features of the PESs of title reactions.

Table I Theoretical and experimental bond dissociation energies (eV).

\begin{tabular}{|cccccc|}
\hline Species & calc & $\exp ^{\mathrm{a}}$ & Species & calc & $\exp ^{\mathrm{a}}$ \\
$\mathrm{SC}-\mathrm{O}$ & 6.93 & $6.88 \pm 0.04$ & $\mathrm{Y}^{+}-\mathrm{O}$ & 7.12 & $7.28 \pm 0.18$ \\
$\mathrm{~S}-\mathrm{CO}$ & 3.10 & $3.140 \pm 0.005$ & $\mathrm{Y}^{+}-\mathrm{S}$ & 5.27 & $5.49 \pm 0.18$ \\
$\mathrm{C}-\mathrm{O}$ & 10.80 & $11.109 \pm 0.005$ & $\mathrm{Y}^{+}-\mathrm{C}$ & 3.16 & $2.91 \pm 0.12$ \\
$\mathrm{C}-\mathrm{S}$ & 6.97 & $7.37 \pm 0.04$ & $\mathrm{Y}^{+}-\mathrm{CO}$ & 0.63 & $0.31 \pm 0.11$ \\
\hline
\end{tabular}

${ }^{\mathrm{a}}$ Ref. 16.

The optimized geometries of the stationary points and structures of the crossing points on the different PESs for the title reactions are depicted in Figure 1. The relevant energies of various compounds in the reaction are listed in Table II and Table III, and the profiles of the PESs are shown in Figure 2. The potential energies curve-crossing diagrams between the different potential energy surfaces are drawn in Figure 3. 

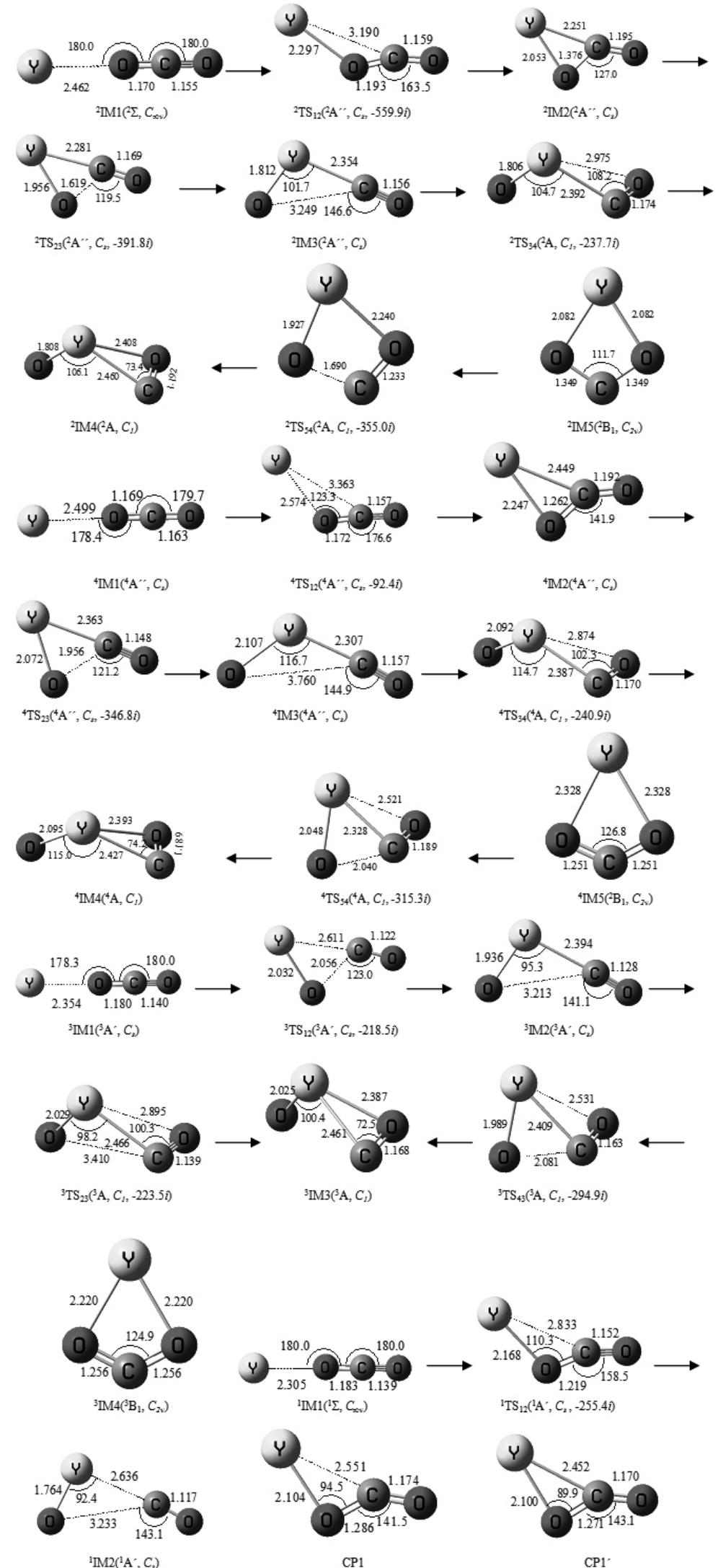

Figure 1. Optimized geometries for the various stationary points and structures of the crossing points located on the $\mathrm{Y}+\mathrm{CO} 2$ and $\mathrm{Y}++\mathrm{CO} 2$ potential energy surfaces (distances in angstroms, angles in degrees). 
Table II Energy of various complexes in the reaction of $\mathrm{Y}$ atom with $\mathrm{CO}_{2}$ (total energy

$E_{T}, Z P E$ corrections have been taken into account, relative energy $E_{R}$ ).

\begin{tabular}{|c|c|c|c|c|c|}
\hline Species & $E_{T} /$ Hartree & $\begin{array}{c}E_{R} / \\
\mathrm{kcal} \cdot \mathrm{mol}^{-1}\end{array}$ & Species & $E_{T} /$ Hartree & $\begin{array}{c}E_{R} / \\
\mathrm{kcal} \cdot \mathrm{mol}^{-1}\end{array}$ \\
\hline${ }^{2} \mathrm{Y}+\mathrm{CO}_{2}$ & -226.169550 & 0.0 & ${ }^{4} \mathrm{Y}+\mathrm{CO}_{2}$ & -226.151504 & 11.3 \\
\hline${ }^{2} \mathrm{IM} 1$ & -226.177566 & -5.0 & ${ }^{4} \mathrm{IM} 1$ & -226.165497 & 2.5 \\
\hline${ }^{2} \mathrm{TS}_{12}$ & -226.174450 & -3.1 & ${ }^{4} \mathrm{TS}_{12}$ & -226.163753 & 3.6 \\
\hline${ }^{2} \mathrm{IM} 2$ & -226.226380 & -35.6 & ${ }^{4} \mathrm{IM} 2$ & -226.191239 & -13.6 \\
\hline${ }^{2} \mathrm{TS}_{23}$ & -226.224595 & -34.5 & ${ }^{4} \mathrm{TS}_{23}$ & -226.140902 & 18.0 \\
\hline${ }^{2} \mathrm{IM} 3$ & -226.254627 & -53.4 & ${ }^{4} \mathrm{IM} 3$ & -226.157627 & 7.5 \\
\hline${ }^{2} \mathrm{TS}_{34}$ & -226.236788 & -42.2 & ${ }^{4} \mathrm{TS}_{34}$ & -226.136283 & 20.9 \\
\hline${ }^{2} \mathrm{IM} 4$ & -226.244378 & -47.0 & ${ }^{4} \mathrm{IM} 4$ & -226.141289 & 16.0 \\
\hline${ }^{2} \mathrm{IM} 5$ & -226.220703 & -32.1 & ${ }^{4} \mathrm{IM} 5$ & -226.180336 & -6.8 \\
\hline${ }^{2} \mathrm{TS}_{54}$ & -226.215014 & -28.5 & ${ }^{4} \mathrm{TS}_{54}$ & -226.125866 & 27.4 \\
\hline${ }^{2} \mathrm{YO}+\mathrm{CO}$ & -226.228939 & -37.3 & ${ }^{4} \mathrm{YO}+\mathrm{CO}$ & -226.118587 & 32.0 \\
\hline${ }^{2} \mathrm{YCO}+{ }^{1} \mathrm{O}$ & -226.891797 & 174.3 & ${ }^{4} \mathrm{YCO}+{ }^{1} \mathrm{O}$ & -225.908886 & 163.6 \\
\hline${ }^{2} \mathrm{YCO}+{ }^{3} \mathrm{O}$ & -225.992769 & 110.9 & ${ }^{4} \mathrm{YCO}+{ }^{3} \mathrm{O}$ & -226.009858 & 100.2 \\
\hline
\end{tabular}

Table III Energy of various complexes in the reaction of $\mathrm{Y}^{+}$cation with $\mathrm{CO}_{2}$ (total

energy $E_{T}, Z P E$ corrections have been taken into account, relative energy $E_{R}$

\begin{tabular}{|cccccc|}
\hline Species & $E_{T^{\prime}}$ Hartree & $\begin{array}{c}E_{R^{\prime}} \\
\mathrm{kcal} \cdot \mathrm{mol}^{-1}\end{array}$ & Species & $E_{T^{\prime}}$ Hartree & $\begin{array}{c}E_{R^{\prime}} \\
\mathrm{kcal} \cdot \mathrm{mol}^{-1}\end{array}$ \\
\hline${ }^{3} \mathrm{Y}^{+}+\mathrm{CO}_{2}$ & -225.945124 & 0.0 & ${ }^{3} \mathrm{YCO}^{+}+{ }^{3} \mathrm{O}$ & -225.793650 & 95.0 \\
${ }^{3} \mathrm{IM} 1$ & -225.981239 & -22.6 & ${ }^{1} \mathrm{Y}^{+}+\mathrm{CO}_{2}$ & -225.900402 & 28.1 \\
${ }^{3} \mathrm{TS}_{12}$ & -225.914307 & 19.3 & ${ }^{1} \mathrm{IM} 1$ & -225.960279 & -9.5 \\
${ }^{3} \mathrm{IM} 2$ & -225.924287 & 13.1 & ${ }^{1} \mathrm{TS}_{12}$ & -225.953969 & -5.5 \\
${ }^{3} \mathrm{TS}_{23}$ & -225.909277 & 22.5 & ${ }^{1} \mathrm{IM} 2$ & -226.034019 & -55.8 \\
${ }^{3} \mathrm{IM}_{3}$ & -225.914668 & 19.1 & ${ }^{1} \mathrm{YO}^{+}+\mathrm{CO}$ & -226.003363 & -36.5 \\
${ }^{3} \mathrm{IM}{ }^{2}$ & -225.968332 & -14.6 & ${ }^{1} \mathrm{YCO}^{+}+{ }^{1} \mathrm{O}$ & -225.664385 & 176.2 \\
${ }^{3} \mathrm{TS}_{43}$ & -225.902184 & 26.9 & $\mathrm{CP} 1$ & -225.963678 & -11.6 \\
${ }^{3} \mathrm{YO}^{+}+\mathrm{CO}$ & -225.891997 & 33.3 & $\mathrm{CP}^{\prime}$ & -225.966566 & -13.4 \\
${ }^{3} \mathrm{YCO}^{+}+{ }^{1} \mathrm{O}$ & -225.692678 & 158.4 & $\backslash$ & $\backslash$ & $\backslash$ \\
\hline
\end{tabular}

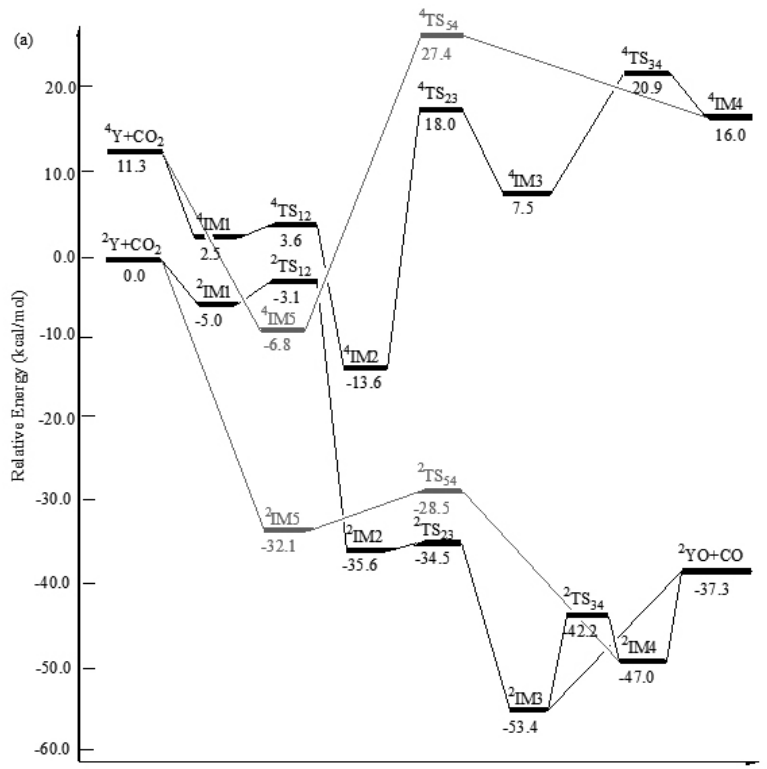

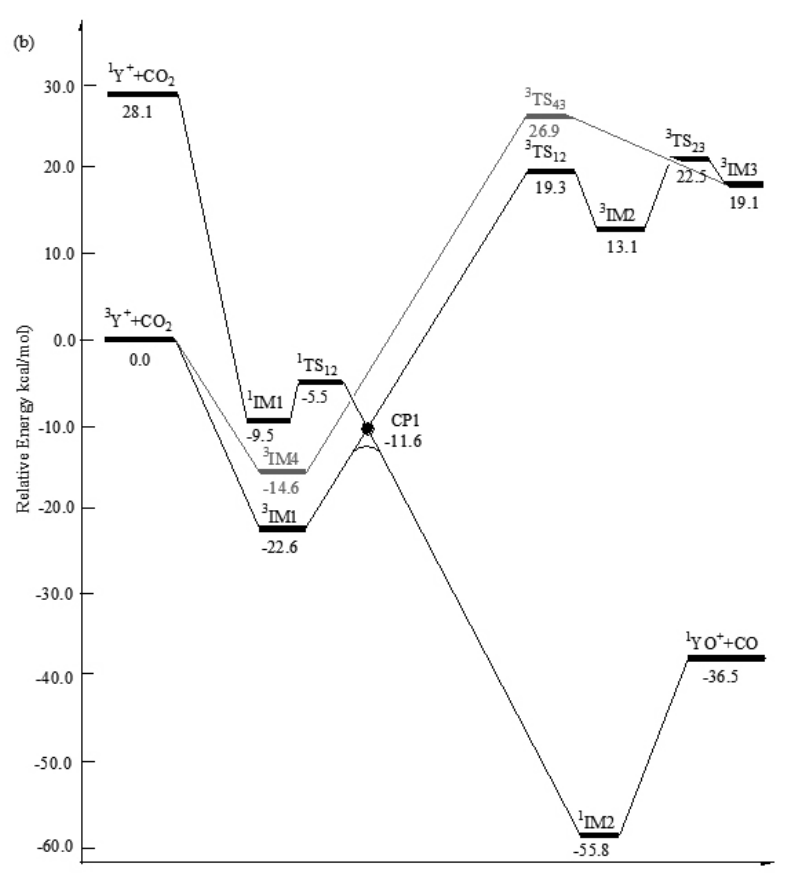

Figure 2. Potential energy surface profiles for the reaction of (a) $\mathrm{Y}$ atom with $\mathrm{CO} 2$; (b) $\mathrm{Y}+$ cation with $\mathrm{CO} 2$.
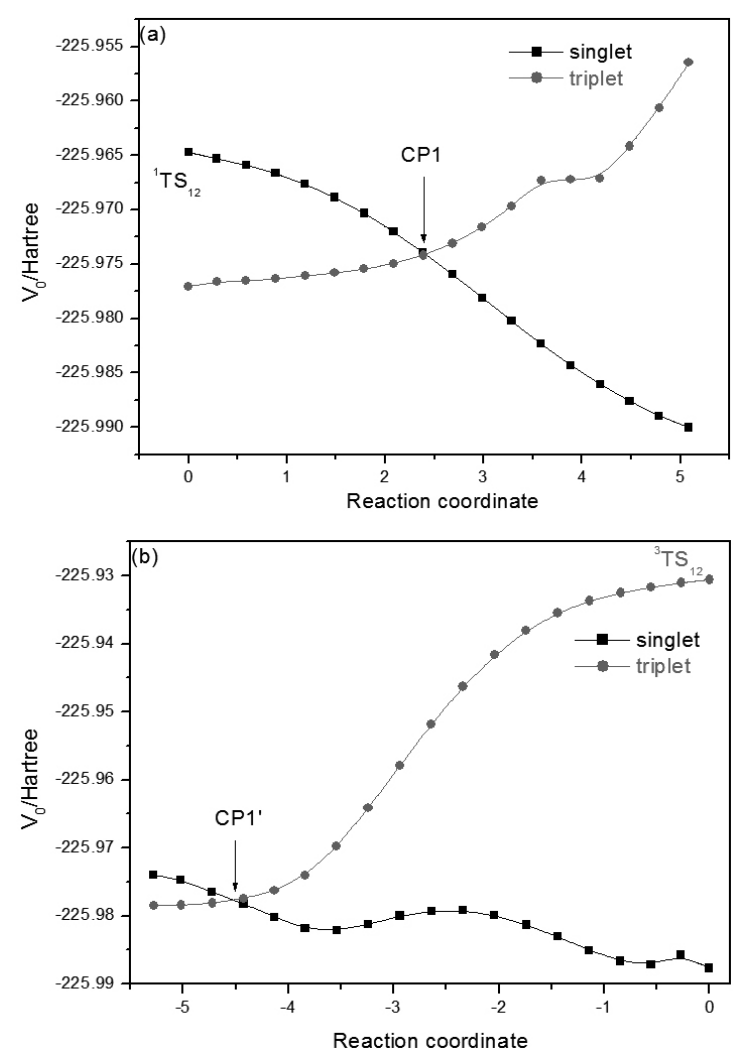

Figure 3. (a) Potential energies from 3IM1 to 1 IM 2 along the triplet IRC; (b) Potential energies from 3IM1 to 1IM2 along the singlet IRC.

THE REACTION BETWEEN Y ATOM AND CO,

The energy of the doublet state $\mathrm{Y}$ atom is lower than that of the excited state (quartet) one by $11.3 \mathrm{kcal} / \mathrm{mol}$ on the chosen calculation level, so the reaction between ground state ${ }^{2} \mathrm{Y}$ and $\mathrm{CO}_{2}$ is more favorable at low energy 
conditions. If $\mathrm{CO}_{2}$ approaches the ground state ${ }^{2} \mathrm{Y}$ atom via its oxygen side, a linear encounter complex denoted as ${ }^{2} \mathrm{IM} 1$ is formed, $5.0 \mathrm{kcal} / \mathrm{mol}$ more stable than the reactants, but it still stores quite high energy. It should be pointed out that although numerous trials are taken to search for possible transition states that connect reactants and original complex, no such transition states are obtained. For example, in the case of the formation of this linear encounter complex ${ }^{2} \mathrm{IM} 1$, for a given $\mathrm{Y}-\mathrm{O}$ bond length, all other geometrical degrees of freedom are optimized, as $\mathrm{Y}$ approaches the $\mathrm{O}$ atom, the energy of the complex descends monotonically until the encounter complex ${ }^{2} \mathrm{IM} 1$ formed. Clearly, the formation of ${ }^{2} \mathrm{IM} 1$ is spontaneous and it is a barrierless process. With reaction proceeding, ${ }^{2} \mathrm{IM} 1$ may reduce its energy through shortening the distances between $\mathrm{Y}$ and $\mathrm{O}, \mathrm{Y}$ and $\mathrm{C}$ atoms respectively until formation of ${ }^{2} \mathrm{IM} 2$. As illustrated in Figure 1, the $\mathrm{Y}-\mathrm{O}$ bond distance in ${ }^{2} \mathrm{TS}$ is shortened from $2.462 \AA$ to $2.297 \AA$, and the $\mathrm{Y}-\mathrm{C}$ bond is shortened to $3.190 \AA$. This step is highly exothermic $(30.6 \mathrm{kcal} / \mathrm{mol})$ with a low energy of $1.9 \mathrm{kcal} / \mathrm{mol}$. Starting from the complex ${ }^{2} \mathrm{IM} 2$, the next step in the reaction mechanism is the insertion of the $\mathrm{Y}$ atom into the $\mathrm{C}-\mathrm{O}$ bond generating ${ }^{2} \mathrm{IM} 3$. This step is exothermic by $17.7 \mathrm{kcal} / \mathrm{mol}$ and requires a low energy barrier of only $1.1 \mathrm{kcal} /$ mol. With the excess energy gained in the formation of ${ }^{2} \mathrm{IM} 2$, the cleavage process can complete very easily. These results show that it is easier for ground state ${ }^{2} \mathrm{Y}$ atom to cleave the $\mathrm{C}-\mathrm{O}$ bond in $\mathrm{CO}_{2}$. The $\mathrm{NBO}$ charge on the $\mathrm{Y}$ atom increases to about $+0.972 e$, whereas the atomic charge on $\mathrm{O}$ atom, decreases to $-0.535 e$ (it is $-0.498 e$ in free $\mathrm{CO}_{2}$ ). The $\mathrm{OY}-\mathrm{CO}$ binding energy is 2.3 $\mathrm{kcal} / \mathrm{mol}$ which can be basically attributed to the $\mathrm{Y}-\mathrm{C}$ bond arising from a $\mathrm{CO} \rightarrow \mathrm{Y} \sigma$-donation and a simultaneous $\mathrm{Y} \rightarrow \mathrm{CO} \pi$-back-donation. The strong interaction of $4 \mathrm{~d}$ orbital of $\mathrm{Y}$ with the $\pi$-antibonding $(\mathrm{C}-\mathrm{O})^{*}$ orbital results in the relatively long $\mathrm{C}-\mathrm{O}$ bond length ( $1.156 \AA$ vs $1.128 \AA$ in free $\mathrm{CO}$ molecule). Further transformation of the ${ }^{2} \mathrm{IM} 3$ complex to $\mathrm{OY}\left(\eta^{2} \mathrm{CO}\right)\left({ }^{2} \mathrm{IM} 4\right)$ goes through the transition state called ${ }^{2} \mathrm{TS}_{34}$ with an energy barrier of $11.2 \mathrm{kcal} / \mathrm{mol}$. ${ }^{2} \mathrm{IM} 4$ is the next most stable species over the doublet PES, which lies $-47.0 \mathrm{kcal} / \mathrm{mol}$ below the reactants. NBO analysis shows that the bonding characteristics of ${ }^{2} \mathrm{IM} 4$ are different from those of ${ }^{2} \mathrm{IM} 3$. The interaction of the orbitals of $\mathrm{Y}$ atom with the $\pi$-antibonding $(\mathrm{C}-\mathrm{O})^{*}$ orbital is slight, and there are only weak bonds between the $\mathrm{C}$ and $\mathrm{Y}, \mathrm{O}$ and $\mathrm{Y}$ atoms, which agrees with the $\mathrm{Y}-\mathrm{O}$ and $\mathrm{Y}-\mathrm{C}$ distances $2.408 \AA$ and $2.460 \AA$ respectively. The NBO charge on the $\mathrm{Y}$ atom increases up to $0.984 e$. This species can be considered as a weakly bounded complex between ${ }^{2} \mathrm{YO}$ and $\mathrm{CO}$, as the dissociation of the insertion product ${ }^{2} \mathrm{IM} 3$ into ${ }^{2} \mathrm{YO}+\mathrm{CO}$ only requires $9.7 \mathrm{kcal} / \mathrm{mol}$ energy at the B3LYP levels. We also considered other dissociation channels from ${ }^{2} \mathrm{IM} 4$, the $\mathrm{Y}-\mathrm{O}$ bond rupture to form ${ }^{2} \mathrm{YCO}^{+}{ }^{1} \mathrm{O}$ and ${ }^{2} \mathrm{YCO}+{ }^{3} \mathrm{O}$, which were calculated to be endothermic by $221.2 \mathrm{kcal} / \mathrm{mol}$ and $157.9 \mathrm{kcal} / \mathrm{mol}$. Obviously, these two dissociation pathways are not feasible.

From Figure 1 and Figure 2(a), one can see that the reactants ${ }^{2} \mathrm{Y}$ and $\mathrm{CO}_{2}$ can form a cyclic $\eta^{2}-\mathrm{OO}$ encounter complex ${ }^{2} \mathrm{IM} 5$, which is $-32.1 \mathrm{kcal} / \mathrm{mol}$ more stable. After passing ${ }^{2} \mathrm{TS}_{54}$, it can rearrange to form ${ }^{2} \mathrm{IM} 4$ easily, with the activation energy only $3.6 \mathrm{kcal} / \mathrm{mol}$. Obviously, compared with the first $\mathrm{C}-\mathrm{O}$ bond activation channel discussed above, this mechanism is more feasible over doublet PES.

With respect to the quartet state pathway, the first step of the reaction on this PES starts with the formation of a nearly linear initial complex ${ }^{4} \mathrm{IM} 1\left({ }^{4} \mathrm{~A}{ }^{\prime \prime}\right.$, C), $8.8 \mathrm{kcal} / \mathrm{mol}$ more stable than reactants ${ }^{4} \mathrm{Y}+\mathrm{CO}_{2}$. Similar with the reaction over the doublet PES, the next step corresponds to the coordinate between $\mathrm{Y}$ and $\mathrm{O}, \mathrm{Y}$ and $\mathrm{C}$ atoms respectively to form a $\eta^{2}-\mathrm{CO}$ encounter complex ${ }^{4} \mathrm{IM} 2\left({ }^{4} \mathrm{~A}^{\prime \prime}, C_{s}\right)$, which is $-24.9 \mathrm{kcal} / \mathrm{mol}$ below the entrance channel ${ }^{4} \mathrm{Y}+\mathrm{CO}_{2}$. Starting from ${ }^{4} \mathrm{IM} 2$, it can rearrange to form ${ }^{4} \mathrm{IM} 3$, which undergoes a rupture of $\mathrm{C}-\mathrm{O}$ bond via a transition state ${ }^{4} \mathrm{TS}_{23}$ that is $31.6 \mathrm{kcal} / \mathrm{mol}$ above ${ }^{4} \mathrm{IM} 2$. As shown in Figure 1, the distance between $\mathrm{Y}$ and $\mathrm{O}$ in ${ }^{4} \mathrm{TS}_{23}$ is shortened from $2.247 \AA$ to $2.072 \AA$. This fact indicates that the weak electrostatic interaction between $\mathrm{Y}$ and $\mathrm{CO}_{2}$ strengthens when it is converted into ${ }^{4} \mathrm{TS}_{23}$, and the $\mathrm{Y}-\mathrm{O}$ bond is nearly formed. The distance between $\mathrm{Y}$ and $\mathrm{C}$ is shortened by $0.086 \AA$, which suggests that the $\mathrm{Y}-\mathrm{C}$ bond is forming. At the same time, the activated $\mathrm{C}-\mathrm{O}$ bond is almost broken, and the bond length is elongated by $0.694 \AA$. Geometrically, one can see that ${ }^{4} \mathrm{TS}_{23}$ is similar to the insertion complex ${ }^{4} \mathrm{IM} 3$, so "TS ${ }_{23}$ is a typical "late" transition state on the quartet PES, this is different from the analogue $\left({ }^{2} \mathrm{TS}_{23}\right)$ on the doublet PES. The imaginary frequency of ${ }^{4} \mathrm{TS}_{23}$ is $346.8 i \mathrm{~cm}^{-1}$, and the normal mode corresponds to the rupture of $\mathrm{C}-\mathrm{O}$ bond with the result of $\mathrm{Y}$ insertion into $\mathrm{C}-\mathrm{O}$ bond.

For the inserted intermediate ${ }^{4} \mathrm{IM} 3$, its electronic state is ${ }^{4} \mathrm{~A}$ " with $C$ symmetry, which is $4.9 \mathrm{kcal} / \mathrm{mol}$ less stable than the encounter complex ${ }^{4} \mathrm{IM} 1$ and $3.8 \mathrm{kcal} / \mathrm{mol}$ lower in energy than the reactants ${ }^{4} \mathrm{Y}+\mathrm{CO}_{2}$, As shown in Figure 1, the $\mathrm{C}-\mathrm{O}$ bond length in ${ }^{4} \mathrm{IM} 3$ is elongated to $3.760 \AA$, which means this bond has ruptured thoroughly. Similar to its doublet counterpart ${ }^{2} \mathrm{IM} 3$, the ${ }^{4} \mathrm{IM} 3$ insertion species can also transform into OY $\left(\eta^{2} \mathrm{CO}\right)$ species named ${ }^{4} \mathrm{IM} 4$, via the transition state ${ }^{4} \mathrm{TS}_{34}$. This step is endothermic by $8.5 \mathrm{kcal} / \mathrm{mol}$ and has a barrier of $13.4 \mathrm{kcal} / \mathrm{mol}$. Clearly, the ${ }^{4} \mathrm{IM} 2$ encounter species is the lowest energy isomer over the quartet PES whereas the $\mathrm{C}-\mathrm{O}$ bond activation complex is difficult to generate due to the relative high activation energy.

Similar with that on the doublet PES, we also located another possible $\mathrm{C}-\mathrm{O}$ bond activation channel over quartet one. As shown in Figure 1 and Figure 2(a), the reactants ${ }^{4} \mathrm{Y}$ and $\mathrm{CO}_{2}$ form a cyclic $\eta^{2}-\mathrm{OO}$ encounter complex ${ }^{4} \mathrm{IM} 5$ first, subsequently, it converts into ${ }^{4} \mathrm{IM} 4$ in the next step, but the activation energy is as high as $34.2 \mathrm{kcal} / \mathrm{mol}$. Clearly, compared with the first channel, this $\mathrm{C}-\mathrm{O}$ bond activation mechanism is not feasible.

After comparing the $\mathrm{C}-\mathrm{O}$ bond activation channels of two different states, one can see the doublet spin state PES is lower in energy than the quartet state by at least $7.2 \mathrm{kcal} / \mathrm{mol}$. In addition, as there is no PES crossing between doublet and quartet state surfaces along the $\mathrm{C}-\mathrm{O}$ bond activation branch, the activation of $\mathrm{C}-\mathrm{O}$ bond in $\mathrm{CO}_{2}$ molecule by $\mathrm{Y}$ atom may proceed throughout over the doublet PES.

\section{THE REACTION BETWEEN $\mathrm{Y}^{+}$CATION AND $\mathrm{CO}_{2}$}

The energy of ${ }^{3} \mathrm{Y}^{+}$cation is lower than that of the singlet by $28.0 \mathrm{kcal} / \mathrm{mol}$ on the chosen calculation level, so the reaction between ${ }^{3} \mathrm{Y}^{+}$and $\mathrm{CO}_{2}$ is more favorable in low energy conditions. As for the triplet PES, the reaction starts with the formation of oxygen-bound encounter complex (YOCO) ${ }^{+},{ }^{3} \mathrm{IM} 1$, which is $22.6 \mathrm{kcal} / \mathrm{mol}$ more stable than the reactants. Along the reaction coordinate, ${ }^{3} \mathrm{IM} 1$ can be converted into an insertion species of $\mathrm{Y}^{+}$cation into the $\mathrm{C}-\mathrm{O}$ bond, ${ }^{3} \mathrm{IM} 2$, which has $C_{\mathrm{s}}$ symmetry with relative energy of $13.1 \mathrm{kcal} / \mathrm{mol}$. The ${ }^{3} \mathrm{IM} 1$ and the inserted structure ${ }^{3} \mathrm{IM} 2$ are connected by ${ }^{3} \mathrm{TS}_{12}$ which has been confirmed by IRC calculation. Geometrically, ${ }^{3} \mathrm{TS}_{12}$ has three-membered ring structure with $C_{s}$ symmetry, and one can see it is similar to ${ }^{3} \mathrm{IM} 2$, so this is a typical "late" transition state on the triplet PES. The relative energy of ${ }^{3} \mathrm{TS}_{12}$ is as high as $19.3 \mathrm{kcal} / \mathrm{mol}$. Therefore, it appears that the $\mathrm{C}-\mathrm{O}$ bond activation on the triplet PES is rather difficult. The next step corresponds to the ${ }^{3} \mathrm{IM} 2 \rightarrow$ ${ }^{3} \mathrm{IM} 3$ isomerization, which involves an activation barrier of $9.4 \mathrm{kcal} / \mathrm{mol}$, and it is endothermic by $9.6 \mathrm{kcal} / \mathrm{mol}$. NBO analysis shows that in both $\mathrm{C}-\mathrm{O}$ bond activation complexes, the $\mathrm{CO} \rightarrow \mathrm{Y} \sigma$-donation is relative strong while the effect of $\mathrm{Y} \rightarrow \mathrm{CO} \pi$-back-donation is very slight.

In addition, we also located a cyclic $\eta^{2}-\mathrm{OO}$ encounter complex ${ }^{3} \mathrm{IM} 4$ over this PES, which is $-14.6 \mathrm{kcal} / \mathrm{mol}$ more stable. After passing ${ }^{3} \mathrm{TS}_{43}$, it can rearrange to form ${ }^{2} \mathrm{IM} 3$, but it requires very high activation energy of 42.1 $\mathrm{kcal} / \mathrm{mol}$. Obviously, compared with the first $\mathrm{C}-\mathrm{O}$ bond activation channel discussed above, this mechanism is not feasible over the triplet PES.

Next let us turn to the singlet reaction path, as depicted in Figure 1 and Figure 2. Similar with that of the triplet path, the first step of the reaction on the singlet path is the formation of an initial complex ${ }^{1} \mathrm{IM} 1$, which will release about $9.5 \mathrm{kcal} / \mathrm{mol}$ energy. The insertion mechanism in the present case is very similar to that of ${ }^{3} \mathrm{Y}^{+}$inserting into the $\mathrm{C}-\mathrm{O}$ bond of $\mathrm{CO}_{2}$. Starting from ${ }^{1} \mathrm{IM} 1$, it can interconvert to ${ }^{1} \mathrm{IM} 2$, which undergoes a rupture of $\mathrm{C}-\mathrm{O}$ bond via a transition state ${ }^{1} \mathrm{TS}_{12}$ that is only $4.0 \mathrm{kcal} / \mathrm{mol}$ above ${ }^{1} \mathrm{IM} 1$, with the excess energy gained in the formation of ${ }^{1} \mathrm{IM} 1$, the cleavage process can complete favoring. Clearly, the oxidative addition of the $\mathrm{C}-\mathrm{O}$ bond by the excited state of ${ }^{1} \mathrm{Y}^{+}$cation is energetically spontaneous and it is a barrier free process. The overall reaction ${ }^{1} \mathrm{Y}^{+}+\mathrm{CO} \rightarrow{ }^{1} \mathrm{IM} 2$ is calculated to be exothermic by $83.8 \mathrm{kcal} /$ mol. It should be pointed out that we have tried to locate the $\left(\mathrm{OY}\left(\eta^{2} \mathrm{CO}\right)\right)^{+}$ species on singlet PES, but all our attempts failed. So, different from triplet state, the $\left(\mathrm{OY}\left(\eta^{2} \mathrm{CO}\right)\right)^{+}$complex does not exist over singlet PES, and the $\mathrm{C}-\mathrm{O}$ bond insertion complex ${ }^{1} \mathrm{IM} 2$ is the most stable species along $\mathrm{C}-\mathrm{O}$ bond activation PES, which is even more stable than the triplet analogue ${ }^{3} \mathrm{IM} 2$ by $68.9 \mathrm{kcal} / \mathrm{mol}$. In addition, as the ${ }^{3} \mathrm{Y}^{+}$cation is calculated to be $28.0 \mathrm{kcal} / \mathrm{mol}$ more stable than ${ }^{1} \mathrm{Y}^{+}$(see Figure 2(b)), we can speculate that the intersystem triplet-singlet crossing occurs during the process of ${ }^{3} \mathrm{Y}^{+}+\mathrm{CO}_{2} \rightarrow{ }^{1} \mathrm{IM} 2$. The aim of our following calculation is to determine the region where the spin inversion occurs, and to acquire the structures and energies of crossing points between the two different potential energy surfaces.

We choose a simple approach suggested by Yoshizawa et al. ${ }^{48}$, for approximately locating the crossing points of two PESs of different multiplicities. The main idea of this approach is to perform a series of singlepoint computations of one spin state along the IRC of the other spin state and vice versa. It should be mentioned here that the crossing points obtained in this way are approximations to true minimum energy crossing points, but the energies of these crossing points provide upper bounds to those of the corresponding minimum energy crossing points.

Using the above method, we computed potential energy profile of the singlet state along the triplet IRC and that of the triplet state along the singlet IRC. In Figure 3(a), one can see that a crossing point CP1 is located before 
${ }^{3} \mathrm{TS}_{12}$ with relative energy of $-11.6 \mathrm{kcal} / \mathrm{mol}$. In Figure $3(\mathrm{~b})$, another crossing point $\mathrm{CP} 1^{\prime}$ is found located after ' ${ }^{1} \mathrm{TS}_{12}$ with relative energy of $-13.4 \mathrm{kcal} / \mathrm{mol}$. The structures of both crossing points are given in Figure 1. According to Yoshizawa et al. ${ }^{48}, \mathrm{CP} 1$ is the energy-maximum crossing point, and CP1' is the energy-minimum crossing point between the triplet and singlet surfaces in the reaction pathway of $\mathrm{C}-\mathrm{O}$ bond activation. So the crossing seam between $\mathrm{CP} 1$ and $\mathrm{CP} 1^{\prime}$ is only $1.8 \mathrm{kcal} / \mathrm{mol}$. Therefore, the reaction may jump from the triplet PES to the singlet PES near the crossing point CP1. As can be seen from Figure 2(b), after passing point CP1, the singlet PES can provide a low-energy reaction pathway toward the inserted complex ${ }^{1} \mathrm{IM} 2$. So, the minimum energy pathway can be described as ${ }^{3} \mathrm{Y}^{+}+\mathrm{CO}_{2} \rightarrow \mathrm{CP} 1 \rightarrow{ }^{1} \mathrm{IM} 2$. The overall reaction is exothermic by $-55.8 \mathrm{kcal} / \mathrm{mol}$. Obviously, this intersystem crossing should be important for the reaction mechanism. The $\mathrm{C}-\mathrm{O}$ bond activation by ${ }^{3} \mathrm{Y}^{+}$cation may occur preferentially on the singlet PES until the formation of insertion complex ${ }^{1}$ IM2. Actually, the reactions catalyzed by metallic systems may often involve a change in the spin states and proceed via a non-adiabatic way on two or more potential energy surfaces, denoted as "two state reactivity" (TSR) ${ }^{49-52}$, which has been confirmed by experimental studies. In previous theoretical researches about $\mathrm{CO}_{2}$ activation by $\mathrm{Nb}^{+}$and $\mathrm{Zr}^{+}$cations, Toscano et al..$^{2,3}$ have ascertained the presence of some spin inversion during the reaction process, $\mathrm{CO}_{2}$ activation mediated by metal cations was found to be an exothermic spin-forbidden process resulting from a crossing between different energetic profiles. In addition, as no $\left(\mathrm{OY}\left(\eta^{2} \mathrm{CO}\right)\right)^{+}$complex exist on singlet PES from our above discussion, we believe the ${ }^{3} \mathrm{Y}^{+}$cation reacting with $\mathrm{CO}_{2}$ molecule may give dominating intermediate $(\mathrm{OYCO})^{+}\left({ }^{1} \mathrm{IM} 2\right)$. Moreover, our calculation predict the further breaking off $\mathrm{Y}-\mathrm{O}$ bond may produce ${ }^{1} \mathrm{YO}^{+}+\mathrm{CO}$ in the end, which requires at least $19.2 \mathrm{kcal} / \mathrm{mol}$ energy.

Further, we have reported the theoretical studies on the reactions of $\mathrm{La}$ and $\mathrm{La}^{+}$with $\mathrm{CO}_{2}{ }^{19}$. The results indicate that similar with that of yttrium atom, the reaction between $\mathrm{La}$ atom and $\mathrm{CO}_{2}$ is most likely to proceed over doublet PES throughout the whole process. As for the reactions between cations and $\mathrm{CO}_{2}$, the lowest energy path corresponds to the $\eta^{1}-\mathrm{O}$ coordination of $\mathrm{CO}_{2}$ followed by the insertion of $\mathrm{La}^{+}$or $\mathrm{Y}^{+}$into the $\mathrm{C}-\mathrm{O}$ bond, the minimum energy reaction path requires the crossing of two adiabatic surfaces with different spin states. Both the reactions between atom or cation with $\mathrm{CO}_{2}$ are energy spontaneously and greatly exothermic. From these facts, we conjecture that the insertion reaction and TSR could be general mechanisms for the reactions of $\mathrm{La}^{+}$and $\mathrm{Y}^{+}$ cations with $\mathrm{CO}_{2}$, despite the fact that $\mathrm{Y}$ is classified as a transition metal and $\mathrm{La}$ as a rare earth.

\section{CONCLUSIONS}

The reactions of $\mathrm{Y}$ atom and $\mathrm{Y}^{+}$cation with $\mathrm{CO}_{2}$ were studied using B3LYP calculations. Both the ground and excited state PESs were checked. The following conclusions can be drawn from the present calculations.

1. The reaction between $\mathrm{Y}$ atom and $\mathrm{CO}_{2}$ is most likely to proceed over doublet PES throughout the whole process. As the insertion reaction of ${ }^{2} \mathrm{Y}$ atom into the $\mathrm{C}-\mathrm{O}$ bond of $\mathrm{CO}_{2}$ requires relative low activation energy, both the $\mathrm{C}-\mathrm{O}$ bond inserted complex ${ }^{2} \mathrm{IM} 3$ and $\mathrm{OY}\left(\eta^{2} \mathrm{CO}\right)$ species ( $\left.{ }^{2} \mathrm{IM} 4\right)$ may form easily. The present calculations support the findings of the early experiment ${ }^{7}$.

2. The theoretical results show that different from that of the $\mathrm{Y}+\mathrm{CO}_{2}$ system, in the reaction between $\mathrm{Y}^{+}$cation with $\mathrm{CO}_{2}$, the minimum energy reaction path is found to be neither on the triplet PES nor on the singlet one. Instead, the minimum energy reaction path requires the crossing of two adiabatic surfaces with different spin states. Specifically, the reaction starts on the triplet PES and ends on the singlet PES. This spin inversion leads to a considerable decrease in the activation barrier height. In addition, as no $\left(\mathrm{OY}\left(\eta^{2} \mathrm{CO}\right)\right)^{+}$species is located on the singlet PES of $\mathrm{Y}^{+}$with $\mathrm{CO}_{2}$, we speculate that for the $\mathrm{Y}^{+}+\mathrm{CO}_{2}$ reaction system, the $\mathrm{C}-\mathrm{O}$ bond insertion species, ${ }^{1} \mathrm{IM} 2$ is the dominant intermediate, whereas the $\left(\mathrm{OY}\left(\eta^{2} \mathrm{CO}\right)\right)^{+}$complex can't form.

\section{ACKNOWLEDGEMENTS}

This work was supported by the Zhejiang Provincial Natural Science Foundation of China under Grant No. Y4090387. The computing center for Fudan university is acknowledged for computer time.

\section{REFERENCES}

[1] W. Leitner, Acc. Chem. Res. 35, 746, (2002).

[2] F. Rondinelli, N. Russo, M. Toscano, Theor. Chem. Acc., 115, 434, (2006).

[3] S. D. Tommaso, T. Marino, F. Rondinelli, N. Russo, M. Toscano, J.
Chem.Theor. Comput., 3, 811, (2007).

[4] Z. H. Kafafi, R. H. Hauge, W. E. Billups, J. L. Margrave, J. Am. Chem. Soc., 105, 3886,(1983).

[5] L. Andrews, T. J.Tague, J. Am. Chem. Soc., 120,13230, (1998).

[6] V. N. Solov'ev, E. V. Polikarpov, A. V. Nemukhin, G. B. Sergeev, J. Phys. Chem A., 103, 6721, (1999).

[7] M. F. Zhou, L. Andrews, J. Am. Chem. Soc., 120, 13230, (1998).

[8] F. Galan, M. Fouassier, M. Tranquille, J. Mascetti, I. Papai, J. Phys. Chem A., 101,2626, (1997).

[9] G. V. Chertihin, L. Andrews, J. Am. Chem. Soc., 117, 1595, (1995).

[10] M. F. Zhou, L. Andrews, J. Phys. Chem A., 103, 2066, (1999).

[11] M. R. Sievers, P. B. Armentrout, Int. J. Mass. Spectrom., 185, 117, (1999).

[12] M. R. Sievers, P. B. Armentrout, Int. J. Mass. Spectrom., 179,115, (1998).

[13] M. R. Sievers, P. B. Armentrout, Inorg. Chem., 38, 397, (1999).

[14] M. R. Sievers, P. B. Armentrout, J. Chem. Phys., 102, 754, (1995).

[15] M. R. Sievers, P. B. Armentrout, Int J. Mass. Spectrom., 179, 103, (1998).

[16] I. Kretzschmar, D. Schroder, H. Schwarz, PB. Armentrout, Int. J. Mass. Spectrom.,

249, 263, (2006).

[17] M. Chen, X. Wang, L. Zhang, Q. Z. Qin, J. Phys. Chem A., 104, 7010, (2000).

[18] X. Wang, M. Chen, L. Zhang, Q. Z. Qin, J. Phys. Chem A., 104, 758, (2000).

[19] G. L. Dai, C. F. Wang, J. Mol. Stru (Theochem)., 909, 122, (2009).

[20] P. F. Souter, L. Andrews, J. Am. Chem. Soc. 119, 7350, (1997).

[21] M. F. Zhou, B. Liang, L. Andrews, J. Phys. Chem A., 103, 2013, (1999).

[22] B. Liang, L. Andrews, J. Phys. Chem A., 106, 595, (2002).

[23] B. Liang, L. Andrews, J. Phys. Chem A., 106, 4042, (2002).

[24] L. Andrews, M. F. Zhou, B. Liang, J. Li, B. E. Bursten, J. Am.Chem. Soc., 122, 11440, (2000).

[25] A. M. L. Quere, C. Xu, L. Manceron, J. Phys. Chem., 95, 3031, (1991).

[26] I. Papai, G. Schubert, Y. Hannachi, J. Mascetti, J. Phys.Chem A., 106, 9551, (2002).

[27] I. Papai, J. Mascetti, R. Fournier, J. Phys. Chem A., 101, 4465, (1997).

[28] I. Papai, Y. Hannachi, S. Gwizdala, J. Mascetti, J. Phys. Chem A., 106, 4181, (2002).

[29] Y. Hannachi, J. Mascetti, A. Stirling, I. Papai, J. Phys. Chem A., 107, 6708, (2003).

[30] Y. Dobrogorskaya, J. Mascetti, I. Papai, Y. Hannachi, J. Phys. Chem A., 109, 7932, (2005).

[31] M. F. Zhou, N. Tsumori, Z. Li, K. Fan, L. Andrews, Q. Xu, J. Am. Chem. Soc., 124, 12936, (2002).

[32] L. Jiang, Q. Xu, J. Am. Chem. Soc., 127, 42, (2005).

[33] Q. Xu, L. Jiang, N. Tsumori, Angew. Chem. Int. Ed., 44, 4338, (2005).

[34] L. Jiang, Q. Xu, J. Am. Chem. Soc., 127, 8906, (2005).

[35] M. L. Campbell, Phys. Chem. Chem. Phys., 1, 3731, (1999).

[36] M. L. Campbell, Chem. Phys. Lett., 330, 547, (2000).

[37] R. Yrsson, J. Mascetti, React. Kinet. Catal. Lett., 285, 107, (2005).

[38] L. Jiang, X. B. Zhang, S. Han, Q. Xu, Inorg. Chem., 47, 4826, (2008).

[39] L. Jiang, Q. Xu, J. Phys. Chem A., 111, 3519, (2007).

[40] Y. C. Wang, X. Y. Yang, Z. Y. Geng, Z. Y. Liu, Chem. Phys. Lett., 431, $39,(2006)$.

[41] A. D. Becke, J. Chem. Phys., 98, 5648. (1993).

[42] C. Lee, W. Yang, R. G. Parr, Phys. Rev B., 37, 785, (1988).

[43] M. C. Holthausen, W. Koch, J. Am. Chem. Soc., 118, 9932, (1996).

[44] M. C. Holthausen, A. Fiedler, H. Schwarz, W. Koch, J. Phys. Chem., 100, 6236, (1996).

[45] M. Dolg, H. Stoll, A. Savin, H. Preuss, Theor. Chim. Acta., 75, 173, (1989).

[46] K. Fukui, Accounts Chem. Res., 14, 363, (1981).

[47] M. J. Frisch et al., Gaussian 03, Revision B04, Gaussian Inc., Pittsburgh PA, 2003.

[48] K. Yoshizawa, Y. Shiota, T. Yamabe, J. Chem. Phys.,111, 538, (1999).

[49] A. Fiedler, D. Schroder, S. Shaik, H. Schwarz, J. Am. Chem. Soc., 116, $3563,(1994)$.

[50] J. N. Harvey, R. Poli, K. M. Smith, Coord. Chem. Rev., 238, 347, (2003).

[51] G. B. Zhang, S. H. Li, Y. S. Jiang, Organometallics., 22, 3820, (2003).

[52] D. Schroder, S. Shaik, H. Schwarz, Acc. Chem. Res., 33, 139, (2000). 